This is the author's final, peer-reviewed manuscript as accepted for publication. The publisher-formatted version may be available through the publisher's web site or your institution's library.

\title{
Design of a garment for data collection of toddler language and physical activity
}

Sherry Haar, Bronwyn Fees, Stewart Trost, Linda K. Crowe, and Ann Murray

\section{How to cite this manuscript}

If you make reference to this version of the manuscript, use the following information:

Haar, S., Fees, B., Trost, S., Crowe, L. K., \& Murray, A. (2013). Design of a garment for data collection of toddler language and physical activity. Retrieved from http://krex.ksu.edu

\section{Published Version Information}

Citation: Haar, S., Fees, B., Trost, S., Crowe, L. K., \& Murray, A. (2013). Design of a garment for data collection of toddler language and physical activity. Clothing and Textiles Research Journal, 31(2), 125-140.

Copyright: (C) The Author(s) 2013

Digital Object Identifier (DOI): doi:10.1177/0887302X13478161

Publisher's Link: http://ctr.sagepub.com/content/31/2/125

This item was retrieved from the K-State Research Exchange (K-REx), the institutional repository of Kansas State University. K-REx is available at http://krex.ksu.edu 


\title{
Design of a Garment for Data Collection of Toddler Language and Physical Activity
}

\author{
Haar, S., Fees, B., Trost, S., Crowe, L. K., \& Murray, A.
}

Financial support for the research was received from Kansas State University Small Research Grant

Abstract: Design process phases of development, evaluation and implementation were used to create a garment to simultaneously collect reliable data of speech production and intensity of movement of toddlers (18-36 months). A series of prototypes were developed and evaluated that housed accelerometer-based motion sensors and a digital transmitter with microphone. The approved test garment was a top constructed from loop-faced fabric with interior pockets to house devices. Extended side panels allowed for sizing. In total, 56 toddlers (28 male; 28 female; 16-36 months of age) participated in the study providing pilot and baseline data. The test garment was effective in collecting data as evaluated for accuracy and reliability using ANOVA for accelerometer data, transcription of video for type of movement, and number and length of utterances for speech production. The data collection garment has been implemented in various studies across disciplines.

Keywords: design process, toddler, physical activity, speech, accelerometer

Health and well-being are primary issues in the development of young children. Concerns about being overweight during childhood and its implication for adulthood have focused on preschool children (3 to 5 years); however, recently, researchers have examined the physical activity of toddlers (18 to 36 months) with the aim of understanding levels and intensity of movement and their contributions to overall health (Trost, Loprinzi, \& Fees, 2010). Researchers are particularly interested in understanding physical activity in the group-care setting given the rapidly increasing percentage of toddlers in such settings (e.g., center-based programs, Early Head Start) (National Center for Education Statistics, 2012) and the call by epidemiologists and public health officials to examine these settings (Story, Kaphingst, \& French, 2006). However, the actual task of measuring activity in these natural environments is yet a challenge to be solved. 
Language and language expression are integrated with movement (Nadon-Gabrion, 1984; Murray, Fees, Crowe, Murphy, \& Henriksen, 2006). Differences in children's language expression can be observed as early as 18 months of age and widen across the preschool years (Allen \& Marotz, 2007). Observations of young children's communicative development and acquisition of motor skills (Wang, 2004) illuminate consistent patterns of language accomplishments and motor milestones throughout this early developmental period. However, there is limited research to date documenting the frequency and complexity of language used during various types of movement in which children engage.

Researchers from disciplines of kinesiology, speech and language pathology, early childhood development and education, and apparel design at a Midwestern university collaborated to address concerns regarding the simultaneous capture of movement and speech in toddlers within childcare environments. The overarching goal of the research team was to develop a method to collect data in a manner both adaptable to toddlers in childcare environments and also flexible across the research team's disciplines.

\section{Background}

\section{Toddler Physical and Developmental Activity}

The National Health and Nutrition Examination Survey (NHANES) reported an increase in the prevalence of obesity in the population overall and in particular for children 2 to 19 years of age (Ogden, Carroll, \& Flegal, 2008). This is particularly alarming given a growing body of research suggesting long term relationships between health behaviors practiced during not only early elementary but also early childhood (preschool) and later adult health stages (Singh, Mulder, Twisk, van Mechelen, \& Chinapaw, 2008). Just how early in life this predictive 
relationship exists, particularly for physical activity, is unclear. Researchers have gradually turned their interests to infants and toddlers to address this question.

A potential predictor of overweight and obesity among young children is intensity of physical activity experienced in daily life both at home (Loprinzi \& Trost, 2010) and within childcare (Story et al., 2006). Pre-kindergarten environments are of particular interest as the proportion of time spent in childcare is second to that spent within the home. Pate, O'Neill, and Mitchell (2010), in their review of methods measuring physical activity types and levels of intensity, concluded that both accelerometry and direct observation systems such as the Children's Activity Rating Scale (CARS) (Baranowski, Thompson, DuRant, Baronowski, \& Puhl, 1993) and the Observational System for Recording Physical Activity in Children preschool version (OSRAC-P) (Brown et al., 2006) are reliable and valid observational measures of activity in preschoolers as compared to other reporting systems and pedometry. Such measures have consistently shown that preschoolers in childcare experience less than 60 minutes of moderate to vigorous physical activity in an 8-hour day, less than the recommended levels of activity by the National Association for Sport and Physical Education, and that sedentary and low levels of activity characterize the preschool child's motor experiences (Reilly, 2010). Examining the activity levels of toddlers is the next logical step to examine the predictive relationship of activity and overweight.

Children aged birth to 5 years typically experience rapid physical growth, coordination of gross motor movements, and development of fine motor skills (Gallahue \& Ozmun, 2006). Cognitively, toddlers are often characterized as extremely curious as understanding of their environments continues to expand. Toddlers experience continued growth in representational thinking (Piaget, 1970) illustrated by their imaginary play including “dress-up,” dual 
representation (DeLoache, 2004), and categorization. Linguistically, toddlers experience rapid growth in receptive and expressive language and in the pragmatics of conversation. Words become a powerful tool for the toddler to control his or her environment as well as for the environment to shape the behaviors of the child.

\section{Wearable Technology}

Wearable technology, also called smart clothing, intelligent clothing, and wearables, is a term used to describe clothing that functions with electronics on the moving body. Begun in the late 1960s with computing devices embedded in everyday objects, the field gained interest with the miniaturization of components in the 1980s and 1990s (Lee, 2005). While early research was conducted for the military, other fields (medical, performance sportswear, communication, and entertainment) have continued to advance the integration of clothing and technology.

Much wearable technology utilizes miniature sensors embedded into the garment to measure data derived from the human body and environment and computed using a microprocessor (Bonato, 2005; Seymour, 2008) that provides personal assessments of health or performance (O’Mahony \& Braddock, 2002). Examples of integrating communication technology into clothing have included keyboards, mobile phones, blue tooth, microphones, MP3 players, radios, cameras, light emitting devices, recorders, speakers, and global positioning systems (Chun \& Ha, 2009; Hofmann, 2004; Palomo-Lovinski, 2008; Seymour, 2008). Wearable technologies developed for the child wearer have addressed safety (Bolton, 2002), creativity (Seymour, 2008), and language analysis (LENA Research Foundation, 2011). Challenges include storing enough energy to run devices; bulkiness of electronic components; durability of traditional garments; re-routing capabilities; water-proofing and wash ability; thermal and 
moisture management; sizing and fit; and concern over surrounding the body with electronics and radio waves (Dunne, Ashdown, \& Smyth, 2005; Lee, 2005).

\section{Problem and Purpose}

Recent studies suggest a relationship between physical activity during early childhood and activity and obesity in adulthood; however, the literature is sparse with respect to activity types and levels during toddlerhood. By contrast, an established line of research indicates the toddler years are formative years for language development. Both areas of research suggest that the quality of the childcare environments may be influential in affecting development currently and longitudinally. Yet, gathering movement and speech data of children in a childcare environment presents challenges. Manipulation and loose fit of the accelerometer against the body (as it is typically attached to a belt around the lower torso) are challenges affecting accurate movement data collection. The main challenges for speech data collection are clarity and isolation of a specific child's speech from surrounding noise (as data is typically captured from a video camera or microphone mounted in the room). Therefore, the purpose of this study was to develop a reliable method of collecting data on the intensity of movement and speech production of toddlers within the childcare environment.

The research objectives were to use the design process to (a) develop a garment to simultaneously gather data on movement intensity and speech production of toddlers, (b) evaluate the garment in test trials for its ability to gather data on movement and speech, and (c) implement the garment in research across disciplines of kinesiology, speech and language pathology, early childhood development and education, and apparel design.

\section{Conceptual Framework}


The design process conceptual framework included three phases: design development, evaluation, and implementation. The process was adapted from LaBat and Sokolowski's (1999) "three-stage design process" (p. 16) of problem definition and research, creative exploration (preliminary ideas, design refinement, prototype development, and evaluation), and implementation (production and refinement). Adaptations were prototype development and pretesting during the first stage, with the second stage focusing on evaluation and the third stage, similar to the original, in the "ultimate consumer," researchers in multiple disciplines, using the product (LaBat \& Sokolowski, 1999, p. 19).

During the design development phase, the researchers developed specifications from their past research experiences and literature review. Based on the specifications, ideas were sketched

and sample products (prototypes) constructed, fitted on representative child models, reviewed by the team, and pre-pilot tested. Specifications were modified throughout based on emergent findings. During the design evaluation phase the garment was pilot tested for effectiveness in collecting and coordinating data from the devices (accelerometers, voice transmitter, and video) in a childcare setting. Observations from the classroom instructors on fit, ease of donning and doffing, perceived comfort, and aesthetics were noted, and the garment was evaluated for dimensional change during laundering. The design implementation phase included the use of the approved garment for additional data collection and use in research across disciplines, with three studies presented as examples.

\section{Design Development}

\section{Design Specifications}

The primary functional requirements were to house data collection devices, accelerometers, and a wireless transmitter with microphone (Figure 1) for accurate collection of 
movement and speech data and to coordinate with video recordings. The ideal location for accelerometer placement is the center of mass and the initial location for the accelerometer was specified at the side hip level; the location changed from hip to waist level during pilot testing in order for a snug fit to be obtained. The specifications for the wireless transmitter and microphone were to accommodate the current equipment being used by the researchers, while allowing for inclusion of future technology. It was necessary for the devices to be located where children could not manipulate them with the microphone near the mouth.

\section{Insert Figure 1}

Other functional requirements included perceived wearing comfort during the 20 minute testing period, snug fit on children aged 18 to 36 months, ease of donning and doffing over clothes of all seasons, and ease of cleaning. Aesthetic requirements were that the product should resemble clothing that 18 to 36 month old children would wear. As future research was planned to examine how interventions, such as a costume prop, influence movement, the initial design was to be a basic style in a solid color. A specification added during pilot testing was that decorative attachments (i.e., smiley faces) be available to promote wearing of the test garment.

\section{Prototype Development}

The role of the initial prototypes (1 through 5) was to establish foundation garments to analyze fit, experiment with fabrics and construction methods, and initiate ideas to house data collection devices. Later prototype versions (6 and 7) were evaluated for the efficacy of data collection for language and movement. In total, seven prototypes were developed with the seventh version acceptable to the research team. 
Prototypes 1-5. A pattern was drafted with measurements from the Commercial Standard CS151-50 (Solinger, 1988) for toddler size 3 with a waist measurement of 21 in. (53.3 $\mathrm{cm}$ ). The first three prototypes (Figure 2) were variations of a sleeveless top in three fabrications: neoprene/spandex knit; nylon/spandex knit; and Veltex ${ }^{\circledR}$, a nylon loop-faced fabric with a thin polyester foam core $(.4 \mathrm{~cm})$ and nylon tricot backing. The loop-faced fabric was preferred as hook tape at openings could connect to the loop surface allowing for ease of donning, doffing, and fitting. Prototypes 4 and 5 (Figure 2), constructed from $.4 \mathrm{~cm}$ and $.6 \mathrm{~cm}$ loop-faced fabric respectively, consisted of front and back panels with variations of pockets to house the devices. The research team evaluated prototypes 4 and 5 by physical inspection and fittings with a sample population of eleven children in order to check for overall feasibility of design. Preferences included the separating front and back feature of Prototype 5, the $.4 \mathrm{~cm}$ loop-faced fabric for the garment, and thicker $(.6 \mathrm{~cm})$ loop-faced fabric for pockets. The accelerometer pocket needed to be smaller to eliminate movement of the device. An additional location to house the accelerometer at center back was requested. The fit session revealed that the prototypes did not accommodate children who were larger than toddler size 3 and the fit on the smaller sized children was too large. Construction methods of turn and stitched edges and use of stretch mesh for cord guides and microphone pocket were acceptable.

\section{Insert Figure 2}

Prototypes 6a and $\mathbf{6 b}$. Based on the team evaluation and another team meeting to discuss pilot testing, two more prototypes, 6a (Figure 3) and 6b, were constructed. Prototype 6a 
was sized to accommodate torso measurements from 18 to 22 in. $(45.7$ to $55.9 \mathrm{~cm})$ and Prototype 6b from 20 to 26 in. (50.8 to $66.0 \mathrm{~cm}$ ).

Insert Figure 3

Pre-pilot testing. The purpose of the test trial prior to pilot testing was to assess if the data collection devices (i.e., digital voice transmitter and accelerometer) were recording data while housed in the garment and to coordinate the timing of video recordings with the transmitter and accelerometer. Four children from the overall sample participated in the 20-minute test trial. Review of the data showed the accelerometer was recording data and the voice recordings were clear and understandable. Prior to moving onto the pilot testing phase, the researchers met and made recommendations for the next prototype.

Changes incorporated into the next prototype were adding pockets for a second brand of accelerometer, an Actical ${ }^{\mathrm{TM}}$, which measured slightly smaller than the ActiGraph ${ }^{\mathrm{TM}}$ (Figure 1). The size of the digital transmitter pocket was reduced to eliminate movement of the device. Fit changes were lowering the necklines, increasing side back extensions, and shortening the length. Two garments in each size were constructed to provide the children the option of wearing a garment when not being tested, which supports the interactive nature of the childcare environment.

Prototypes $7 \mathbf{a}$ and $7 \mathbf{b}$. Prototypes $7 \mathrm{a}$ and $7 \mathrm{~b}$ were created for the evaluation and pilot data collection phase. See Figures 4 and 5. The fabric remained the same from Prototype 6 with black, $.4 \mathrm{~cm}$ thick Veltex ${ }^{\circledR}$ fabric for the garment, $.6 \mathrm{~cm}$ thick Veltex ${ }^{\circledR}$ fabric for the accelerometer and transmitter pockets, and stretch mesh for the microphone and cord guides. 


\section{Insert Figures 4 and 5}

The garment front had a scoop neck, extended shoulders with hook tape to facilitate fitting, donning, and doffing. The microphone was housed in an interior stretch mesh pocket at the right shoulder. The front sides were extended toward the back beyond the normal side seam to facilitate a range of torso widths. Hook tape was stitched to the side edge front interior in order to adhere the front extension to the back panel loop-faced fabric for a snug fit. Pockets for the ActiGraph ${ }^{\circledR}$ and Actical ${ }^{\circledR}$ accelerometers were side by side on the interior left side at waist level. The pocket openings were secured with hook tape. The back panel accommodated the digital transmitter, the cord connecting the transmitter and microphone, and the second location for the accelerometers. Turning and stitching finished the garment edges. Fabric smiley faces $(3.5 \mathrm{~cm})$ with hook tape on the back side were available for the child to attach to the garment loop-faced fabric.

\section{Design Evaluation}

\section{Pilot Testing}

During the design evaluation phase, Prototype 7 (test garment or data collection garment) was pilot tested to ensure the updated version was allowing for coordination and collection of data from two brands of accelerometers, language through the transmitter, and physical activity from video recordings. Observations were noted by classroom instructors regarding garment fit, donning and doffing, perception of comfort, and aesthetics. In addition, the test garment was evaluated for dimensional change after laundering.

Participants. Sixteen toddlers (6 male; 10 female; $M=28.42$ months), ranging in age from 16 to 36 months, from two childcare programs in a Midwestern college town participated in 
the pilot test phase which spanned five months. Children had parental or guardian informed consent.

Procedure. Researchers arrived early to the facility to meet with the children, allowing the children time to become accustomed to their presence and recording equipment. A researcher placed the accelerometers, transmitter, and microphone in the appropriately sized test garment. The researcher managing the recorder stood in a corner of the room, out of the way of the staff and children. The researchers did not initiate play or conversation. Data was collected during the morning across the span of data collection.

Participating children were randomly selected upon arrival to wear the test garment. When putting on the garment, the lead teachers were instructed to say, "It is your turn to put on the vest!” or "It is your turn to play dress up!” to encourage participation. A child’s refusal was honored, and another child was offered a turn to wear the test garment. Children who refused were invited again on a subsequent day. The remaining three garments were available to children who wanted to wear the "dress up vest," allowing more children to become comfortable with the garment and minimize quarrelling about who was wearing the test garment.

Recording time was 20 minutes, after which recording stopped, and the test garment was taken off the child. Another target child was then invited to wear the test garment. No planned interventions to stimulate movement or talking were offered unless the teacher had planned for it during the normal course of the morning.

\section{Accelerometer Analysis}

In order to determine if the test garment was an effective method to collect intensity of movement data, accelerometer counts were compared to physical activity ratings. Physical activity intensity was coded using a modification of the Children's Activity Rating Scale (CARS) 
whereby a 4-category scheme was implemented as follows: (a) lying down or sitting, (b) standing, (c) walking, and (d) running. Activity intensity was coded directly from the video tape recording using BEST ${ }^{\mathrm{TM}}$ (Behavioral Evaluation System and Taxonomy), a computerized direct observation software tool (Sharpe \& Koperwas, 2003). The videotaped play sessions were coded by two trained research assistants whose inter-observer agreement was 0.95 . A weighted average CARS score corresponding to each 15 second epoch of the accelerometer output was calculated by multiplying each numeric activity code by the percentage of the 15 second time interval in that code and summing the products. Scores of less than 2.0 were classified as sedentary, scores between 2.0 and 2.99 as light physical activity, and scores greater than or equal to 3.0 were classified as moderate to vigorous physical activity. Differences in accelerometer counts were evaluated using one-way repeated measures ANOVA.

For both accelerometers, counts increased significantly as physical activity increased from sedentary to moderate/vigorous physical activity (Figure 6). Pairwise comparisons indicated that mean activity counts recorded during light intensity intervals were significantly greater than counts recorded during sedentary intervals, while activity counts recorded during moderate/vigorous intervals were significantly higher than those recorded during light and sedentary intervals. Thus, both accelerometer brands performed accurately while housed in the data collection garment pockets at side waist; however, the Actical ${ }^{\mathrm{TM}}$ accelerometer recorded more counts of movement. The center back location was not used due to the additional weight of the accelerometers above the already heavy transmitter.

\section{Insert Figure 6}




\section{Speech Analysis}

The purpose of the speech analysis was to determine if the test garment was an effective method to record toddler vocal productions in coordination with type of movement to determine language use with movement type (Crowe, Fees, Haar, Murray, \& Jensen, 2009). The speech recordings were transcribed and analyzed for number of verbalizations and mean length of utterance (MLU) for each intelligible utterance. Each 20 second segment of movement was categorized using the original five CARS categories of: (a) stationary, (b) stationary with movement of arms or limbs, (c) slow or easy, (d) moderate to non-vigorous, and (e) fast (Puhl, Greaves, Hoyt, \& Baranowski, 1990). The movement and utterance data were juxtaposed to determine mean number and length of utterances during each type of movement (Table 1). On average, the toddlers spoke most frequently during movement described as "stationary with movement of arms or limbs" with 620 total utterances $(M=51.6)$. The average length of utterance was highest in this movement category as well, resulting in an MLU of 3.33 morphemes (i.e., word and word endings). Hence, the test garment was an effective method to record toddler speech productions with preliminary data indicating that the best activities for eliciting more frequent and complex responses may be in a stationary seated or standing position that allows free movement of their limbs, while children moving with more intensity may be less likely to engage in interactive oral communication.

Insert Table 1

\section{Instructor Observations}


In addition to evaluating the test garment for accurate data collection of movement and language, the physical garment was evaluated by the classroom instructors for fit, donning and doffing, perceived comfort, and aesthetics. The instructors noted a snug fit was easily obtained with the adjustable side closures; the garment appeared comfortable and was soft against the skin. Overall the instructors did not like the black color of the fabric and thought primary or secondary colors would be more appropriate. As Veltex ${ }^{\circledR}$ can be custom ordered in other colors, multiple colors is an option to explore in the future. Since a large minimum quantity was needed for a custom order, other colors were not pursued due to time and cost constraints. The instructors noted that while a few children were initially distracted by wearing the garment—as demonstrated by frequent touching and some twisting of the torso - the addition of incentives (decorative smiley faces) reduced children's distraction and increased psychological comfort.

\section{Dimensional Change}

Dimensional change is the changes in length or width of a fabric subjected to specified laundering conditions, with the change expressed as a percentage of the initial dimensions (American Association of Textile Chemists and Colorists [AATCC], 2009). The test garment was evaluated for dimensional changes when subjected to home laundering procedures as specified by the AATCC, Test Method 150-2003 (AATCC, 2009). The laundry procedures were a $4.0 \mathrm{lb}$ load with the garment and ballast laundered at $29^{\circ} \mathrm{C}$, with $66 \mathrm{~g}$ of 1993 AATCC Standard Reference Detergent in an 18 gal wash load. Following washing, the garment was hung on a hanger for air-drying. Three cycles of washing and drying were completed. The dimensional change for length was shrinkage by approximately $5 \%$ and shrinkage in width at 1.6\%. (See Figure 7.) Even though there is no grainline in Veltex ${ }^{\circledR}$, there is more flexibility in the lengthwise direction which resulted in the negative change in dimension. The $5 \%$ change was 
acceptable as the fabric has the flexibility to stretch back to size when in use. The Veltex ${ }^{\circledR}$ served as a washable fabric, which is essential for any garment used by multiple children.

\section{Insert Figure 7}

\section{Design Implementation}

During the design implementation phase, researchers utilized the test garment (prototype 7 or data collection garment) to gather data on toddler speech production and intensity of physical activity with a larger sample. This data collection occurred over a two-year span, providing an expanded data set for the researchers to analyze specific research problems within their domain. The data collection procedures were the same as those presented in the Design Evaluation pilot testing phase. Following is a description of the expanded data set sample and abstracts of three studies in which the expanded data set was or is being used. These studies were selected to show how the research team has implemented the test garment and expanded data set to conduct research across disciplines.

\section{Participants}

Children were invited to participate from two center-based, childcare programs in a rural Midwestern city (population 50,000). Parents and guardians provided informed consent. A total of 40 children participated ( $M=26.9$ mo; SD = 4.5; range 19 to 36 mo; 22 males; 18 females). There were no defining criteria for participation other than age restrictions.

\section{Study One}

The purpose of the study was to derive accelerometer cut-points for sedentary, light, and moderate-to-vigorous physical activity in toddlers and to evaluate the predictive validity of the 
new toddler cut-points to an independent sample as well as to established cut-points for preschool children (Trost, Fees, Haar, Murray, \& Crowe, 2012). The sample for deriving toddler accelerometer cut-points was 22 participants from the first year of the expanded data set, and the independent or cross validation sample was 18 participants from the second year. Data collection procedures were the same as presented in the pilot testing section of the current paper. Physical activity intensity was coded using a modified CARS, and activity intensity was coded using a $\mathrm{BEST}^{\mathrm{TM}}$. Receiver-operating characteristic curve analysis was conducted to identify the count threshold, and Wilcoxon rank sum test for paired samples was used to analyze differences between predicted and observed physical activity. Count thresholds were $0-48,49-418$, and $>418$ counts for sedentary, light, and moderate to vigorous physical activity, respectively. Threshold classification accuracy was excellent for moderate to vigorous physical activity and fair for sedentary activity. When comparing predicted toddler cut-points and established preschool cutpoints to observed counts, time spent in sedentary activity was significantly overestimated, time spent in light physical activity was significantly underestimated, and moderate to vigorous physical activity had no significant differences between the predicted and observed counts. Thus, the accelerometer housed in the test garment provided useful group-level estimates for moderate to vigorous physical activity of toddlers.

\section{Study Two}

The aim of the study was to assess the effects of a costume prop on toddler's frequency and intensity of physical activity, as well as levels of social engagement within the context of the childcare environment (Cleary, 2011). The researchers created a cape and decorative shapes to attach to the data collection garment and gathered data using the same procedures as described in the pilot testing section of this paper. Sixteen costume intervention participants were matched to 
a comparison group of 26 toddlers based on age and gender drawn from the expanded data set. Intensity and frequency of movement and social participation were coded using OSRAC-P and analyzed with ANOVA. The intervention (costume) group exhibited significantly greater social engagement in onlooker, solitary, and parallel play. Surprisingly, the comparison group exhibited a higher mean frequency of gross motor movements than the intervention group; further, no differences in the intensity levels of physical activity were found between the intervention and comparison groups, which may be explained by the controlled environment of the childcare center.

\section{Study Three}

The purpose of a study currently underway is to examine teacher language for encouragement or suppression of child physical activity in the childcare setting. The expanded data set is being coded for utterance type and frequency and physical activity type and frequency. It is predicted that teachers will communicate most often to support language growth during sedentary activity, rather than using language to encourage moderate to vigorous physical activity.

\section{Summary and Conclusions}

The purpose of this research was to use the design process of design development, evaluation, and implementation to create a garment to be worn by toddlers to collect speech production and intensity of physical activity data during typical interactions in the childcare setting in order to evaluate the garment for efficacy of data collection, as well as implement the garment in research across disciplines of kinesiology, speech and language pathology, early childhood development and education, and apparel design. During the design development phase, design specifications for devices, fit, and aesthetics were developed into a series of 
prototypes. The sixth prototype was pre-pilot tested with four participants to verify coordination and data collection from devices (accelerometer, digital voice transmitter, and video). The final prototype, the data collection or test garment, resembled a sleeveless top, was constructed from loop-faced fabric with adjustable hook tape closures at the sides and shoulders, and had inner pockets for accelerometers, digital transmitter, and microphone. The garment was made in two sizes and had decorative attachments.

In the evaluation phase, the data collection garment was pilot tested for efficacy of data collection, fit, and laundering. Significant differences between accelerometer counts categorized as sedentary, light, or moderate to vigorous physical activity validated the test garment as an effective method to collect movement data. The test garment was also an effective method to record speech in coordination with movement type. Findings showed that toddlers spoke most frequently and for longer periods of time while stationary with movement of limbs. Classroom instructors noted the test garment fit was snug, easy to take on and off, and appeared comfortable. The test for dimensional changes to laundering resulted in an acceptable $5 \%$ length shrinkage and $1.6 \%$ width shrinkage.

During the design implementation phase, the data collection garment was used to expand the data set over a two-year span with 40 toddlers. The expanded data set has been used across disciplines to establish accelerometer thresholds for physical activity of toddlers, to assess the role of a costume prop in toddler physical activity and social engagement, and to examine teacher language for encouragement or suppression of toddler physical activity.

Thus, the design process was an appropriate framework to guide the development, evaluation, and implementation of a test garment. The data collection garment was an effective method of gathering movement and speech data of toddlers in the childcare setting. The design 
was appropriate for children in that it could be sized, was washable, and was easy to don and doff. The data collection garment was flexible in its ability to respond to research across disciplines. The design is uncomplicated, allowing different researchers and childcare providers to readily use the test garment.

The flexible and highly portable data collection garment provided researchers studying toddler activity and speech with a reliable and valid method of collecting data within varying types and locations of childcare environments. Data will contribute to monitoring type and intensity of child activity and communication development to promote appropriate physical activity as part of health promotion and language development in toddlers.

\section{Limitations and Future Research}

A limitation of the study was that the data collection garment was evaluated on typically developing toddlers within center-based care settings. Future studies will test in other care environments including family childcare homes in both urban and rural settings as well as children with a range of developmental disabilities.

Even though the data collection garment was effective, there were a few recommended changes. While there were two sizes available and size adjustability at both shoulders and sides, most often the small sized garment was selected and the snug fit was accomplished by adjusting one side closure while keeping the other openings attached. Therefore, the next version of the data collection garment will use the small garment length with the measurements from the large garment side extensions. In addition, only one shoulder will have the option of opening for ease of putting on the garment. The data collection garment had four accelerometer pockets to compare two accelerometers at two locations. The next garment will only include one pocket 
sized to fit commercially available monitors at the side waist to facilitate the practice of data collection.

The use of loop-faced fabric for the garment and hook tape as a closure created a snug fit against the toddler's torso; however, the hook tape was challenging as it stuck to other surfaces such as the child's sweater. Therefore, it is recommended that during testing the child dresses in woven shirts or knit t-shirts. In addition, over time the hook tape began to stretch and distort the side extension it was hooked to during wear. The researchers communicated with an associate from Velcro to identify a hook product that wasn't as aggressive; however, no such product was available. Therefore, future versions of the garment should explore other closure options or ways to stabilize the side extensions.

\section{References}

American Association of Textile Chemists and Colorists [AATCC] (2009). 2009 Technical Manual of the American Association of Textile Chemists and Colorists (Vol. 84). Research Triangle Park, NC: Author.

Allen, K. E., \& Marotz, L. R., (2007). Developmental profiles: Pre-birth through twelve (5th ed.). Clifton Park, NY: Thomson Delmar Learning.

Baranowski, T., Thompson, W. O., DuRant, R. H., Baranowski, J., \& Puhl, J. (1993).

Observations on physical activity in physical locations: Age, gender, ethnicity, and month effects. Research Quarterly for Exercise and Sport, 64(2), 127-133.

Bolton, A. (2002). The supermodern wardrobe. London: V \& A Publications.

Bonato, P. (2005). Advances in wearable technology and applications in physical medicine and rehabilitation. Journal of NeuroEngineering and Rehabilitation, 2(1), 2.

Brown, W. H., Pfeiffer, K. A., McIver, K. L., Dowda, M., Joao, C., Almeida, A. M., \& Pate, R. 
R. (2006). Assessing preschool children’s physical activity: The observational system for recording physical activity in children-preschool version. Research Quarterly for Exercise and Sport, 77(2), 167-176.

Chun, J-H. \& Ha, J-S. (2009). Development of a ubiquitous fashionable computer recording jacket design. International Journal of Fashion Design, Technology and Education, 2(1), $13-22$.

Cleary, M. L. (2011). The relationship between a costume prop and a toddler's type and intensity of movement and social participation (Master's thesis, Kansas State University). Retrieved July 9, 2012, from http://hdl.handle.net/2097/14079

Crowe, L. K., Fees, B., Haar, S. J, Murray, A., \& Jensen, S. (2009, November). Effects of movement type on toddler's expressive language. Poster presented at the Annual Conference of the American Speech-Language-Hearing Association, New Orleans, LA.

DeLoache, J. S., (2004). Becoming symbol-minded. Trends in Cognitive Science. 8(2), 66-70. doi: 10.1016/j.tics.2003.12.004

Dunne, L. E., Ashdown, S. P., and Smyth, B. (2005). Expanding garment functionality through embedded electronic technology. Journal of Textile and Apparel Technology and Management. 4(3), 1-11.

Gallahue, D. L., \& Ozmun, J. C. (2006). Motor development in young children. In Spodek, B. \& O. Saracho (Eds.), Handbook of research on the education of young children (2nd ed., pp. 105-120). Mahwah, NJ: Lawrence Erlbaum Associates Publishers.

Hofmann, I. (2004). Intelligent clothing, innovative concepts. Textile Asia, 35(1), 62-66.

Labat, K. L., \& Sokolowski, S. L. (1999). A three-stage design process applied to an industryUniversity textile product design project. Clothing and Textiles Research Journal, 17(1), 
11-20.

Lee, S. (2005). Fashioning the future: Tomorrow's wardrobe. London: Thames \& Hudson.

LENA Research Foundation. (2011), Automatic language assessment in three easy steps. Retrieved January 3, 2012, from http://www.lenafoundation.org/ProSystem/Overview.aspx

Loprinzi, P. D., \& Trost, S. G. (2010). Parental influences on physical activity behavior in preschool children. Preventive Medicine, 50(3), 129-133.

Murray, A. D., Fees, B. S., Crowe, L. K., Murphy, M. E., \& Henriksen, A. L. (2006). The language environment of toddlers in center-based care vs. home settings. Early Childhood Education Journal, 34(3), 233-239.

Nadon-Gabrion, C. (1984). Language, a bridge to learning in movement and music. Theory in Practice, 23(4), 335-339.

National Center for Education Statistics (2011). Table 1. Percentage distribution of children from birth through age 5 and not yet in kindergarten participating in various weekly nonparental care arrangements, by child and family characteristics: 2005. Retrieved January 8, 2012, from http://nces.ed.gov/pubs2006/earlychild/tables/table_1.asp?referrer=report

Ogden, C. L., Carroll, M. D., \& Flegal, K. M. (2008). High body mass index for age among US children and adolescents, 2003-2006. Journal of the American Medical Association, 299(20), 2401-2405.

O’Mahony, M. \& Braddock, S. E. (2002). Sportstech: Revolutionary fabrics, fashion and design. New York, NY: Thames \& Hudson.

Pate, R. R., O’Neill, J. R., \& Mitchell, J. (2010). Measurement of physical activity in preschool children. Medicine \& Science in Sports \& Exercise, 42(3), 508-512. 
Piaget, J. (1970) Piaget’s theory. In L. Carmichael \& P. H. Mussen, (Eds.) Manual of Child Psychology (Vol.3, $3^{\text {rd }}$ ed., pp 703-732), New York, NY: Wiley.

Palomo-Lovinski, N. (2008). Extensible dress: The future of digital clothing. Clothing and Textiles Research Journal, 26(2), 119-130.

Puhl, J., Greaves, K., Hoyt, M., \& Baranowski, T (1990). Children's activity rating scale (CARS): Description and calibration. Research Quarterly for Exercise \& Sport, 61(1), 26-36.

Reilly, J. J. (2010). Low levels of objectively measured physical activity in preschoolers in child care. Medicine and Science in Sports and Exercise, 42(3), 502-507.

Seymour, S. (2008). Fashionable technology: The interaction of design, fashion, science, and technology. New York, NY: Springer Wien New York.

Sharpe, T. L. \& Koperwas, J. (2003). Behavior and sequential analyses: Principles and practice. Thousand Oaks, CA: Sage Publications.

Singh, A. S., Mulder, C., Twisk, J. W., van Mechelen, W., \& Chinapaw, M. J. (2008). Tracking of childhood overweight into adulthood: A systematic review of the literature. Obesity Reviews, 9(5), 474-488.

Solinger, J. (1988). Apparel manufacturing handbook: analysis, principles and practice (2nd ed.). Columbia, SC: Bobbin Media Corp.

Story, M., Kaphingst, K. M., \& French, S. (2006). The role of child care setting in obesity prevention. The Future of Children,16(1), 143-168.

Trost, S. G., Fees, B. S., Haar, S. J., Murray, A. D., \& Crowe, L. K. (2012). Identification and validity of accelerometer cut-points for toddlers. Obesity, 20(11), 2317-2319.

Trost, S., Loprinzi, P., \& Fees, B. (2010, May). Identification of accelerometer cut-points for 
toddlers. Paper presented at the International Society of Behavior Nutrition and Physical Activity, Minneapolis, MN.

Wang, J. H-T. (2004). A study on gross motor skills of preschool children. Journal of Research in Childhood Education, 19(1), 32-43. 


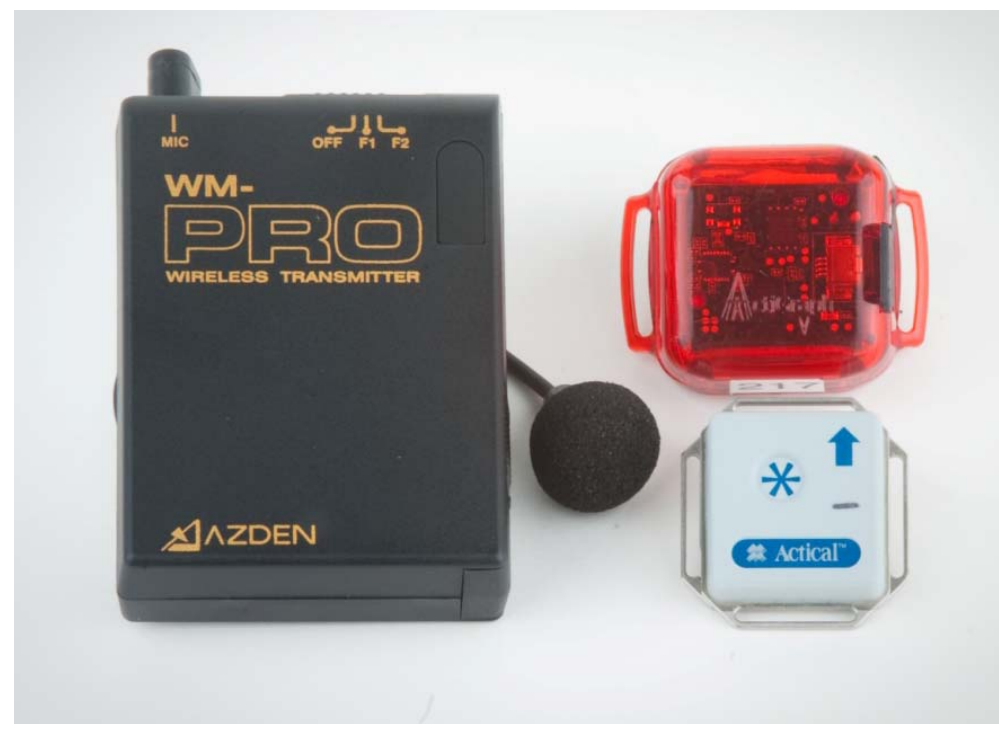

Figure 1. Wireless transmitter with microphone measuring 5.8 x $9.7 \times 2.5 \mathrm{~cm}(\mathrm{w} \times \mathrm{h} \mathrm{x} \mathrm{d})$, ActiGraph $^{\mathrm{TM}}$ accelerometer (upper right) $4.8 \times 4.0 \times 2.0 \mathrm{~cm}$, and Actical ${ }^{\mathrm{TM}}$ accelerometer (lower right) 4.0 x 3.6 x $1.0 \mathrm{~cm}$. Photo by David Mayes. 


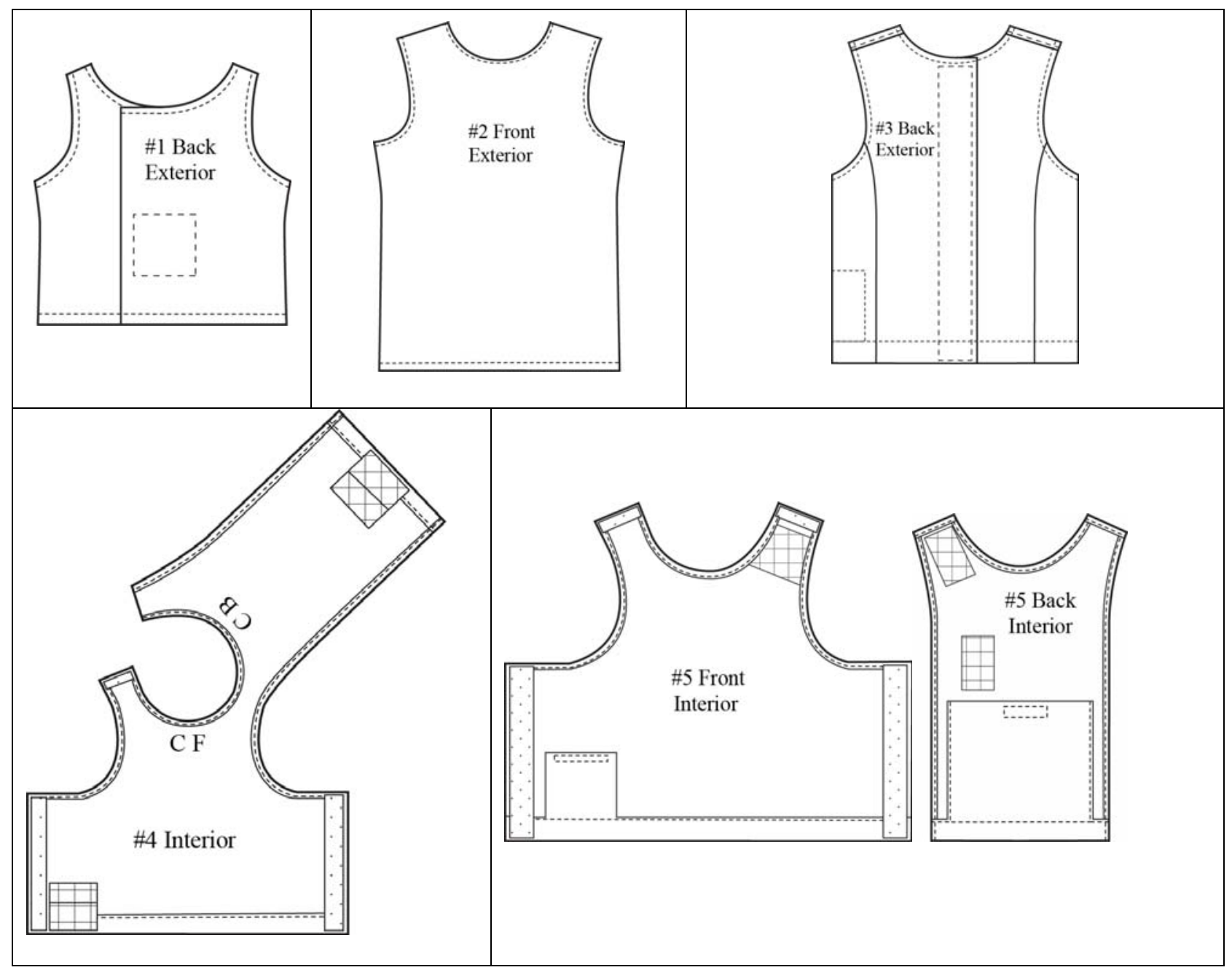

Figure 2. Prototype versions 1 through 5 generated during the design development phase. 


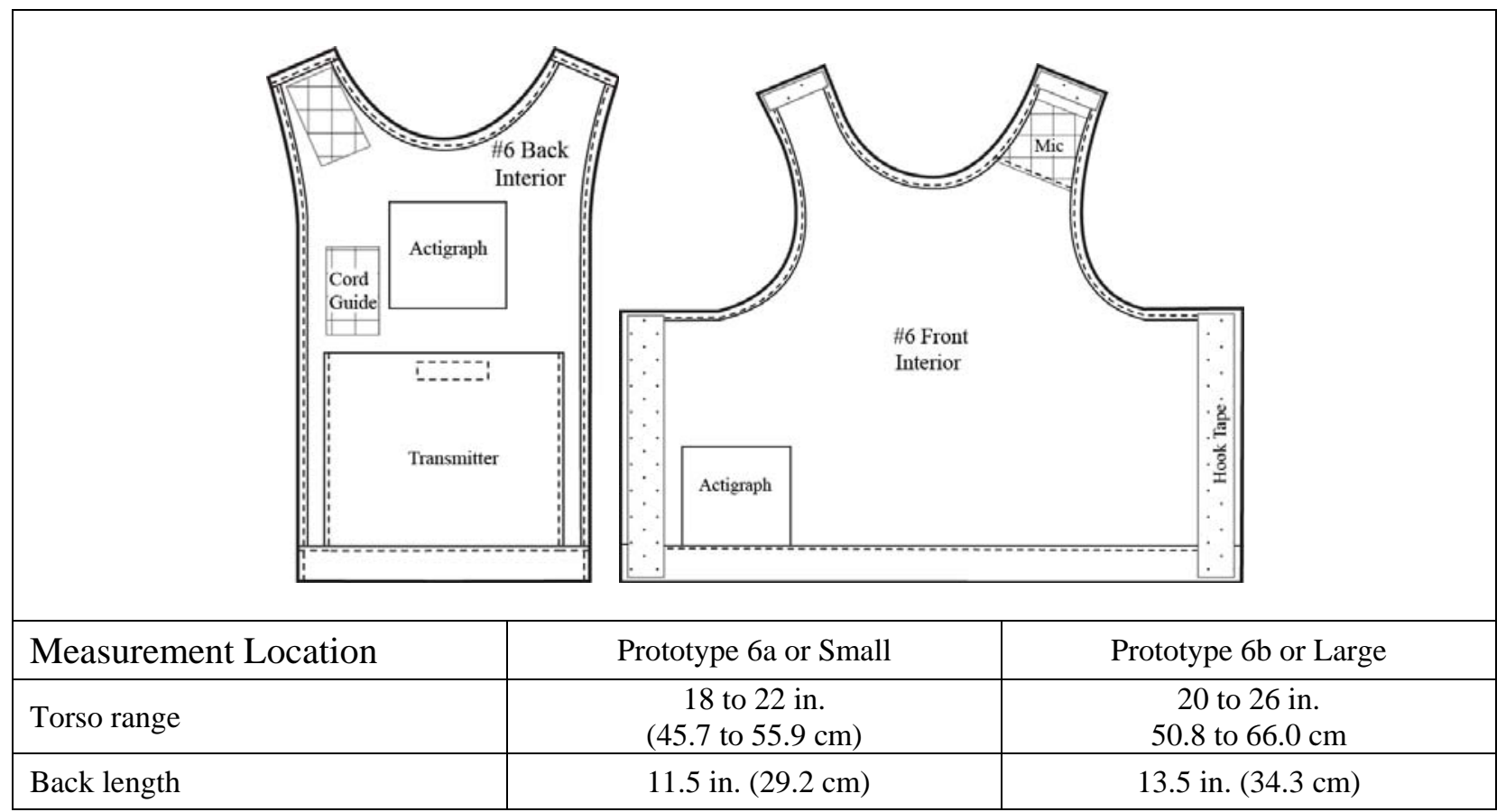

Figure 3. Prototype 6a shown in small size with measurements for small (6a) and large sizes (6b). 


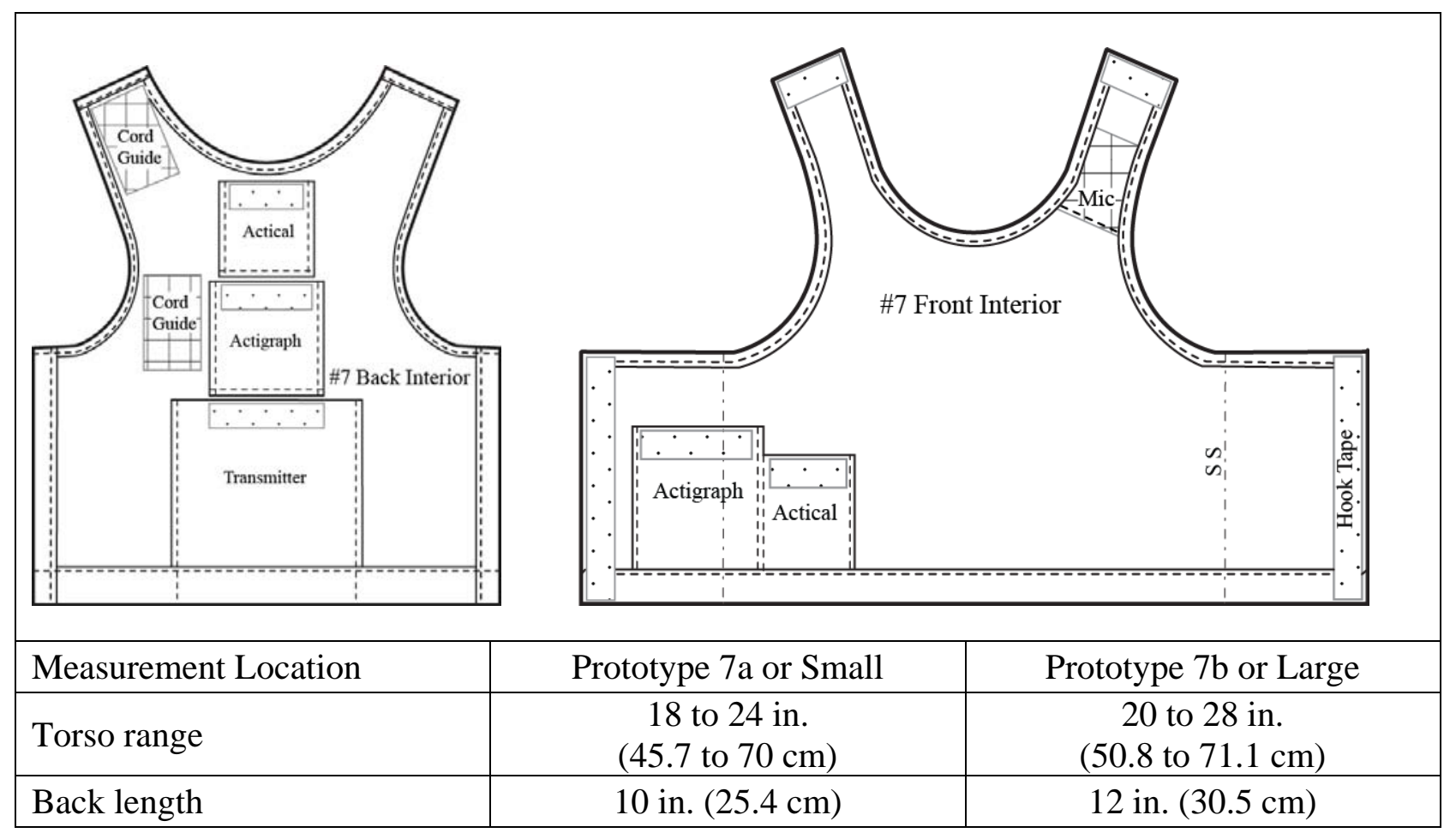

Figure 4. Prototype 7 (test garment or data collection garment) shown in small size with measurements for small (7a) and large sizes (7b). 

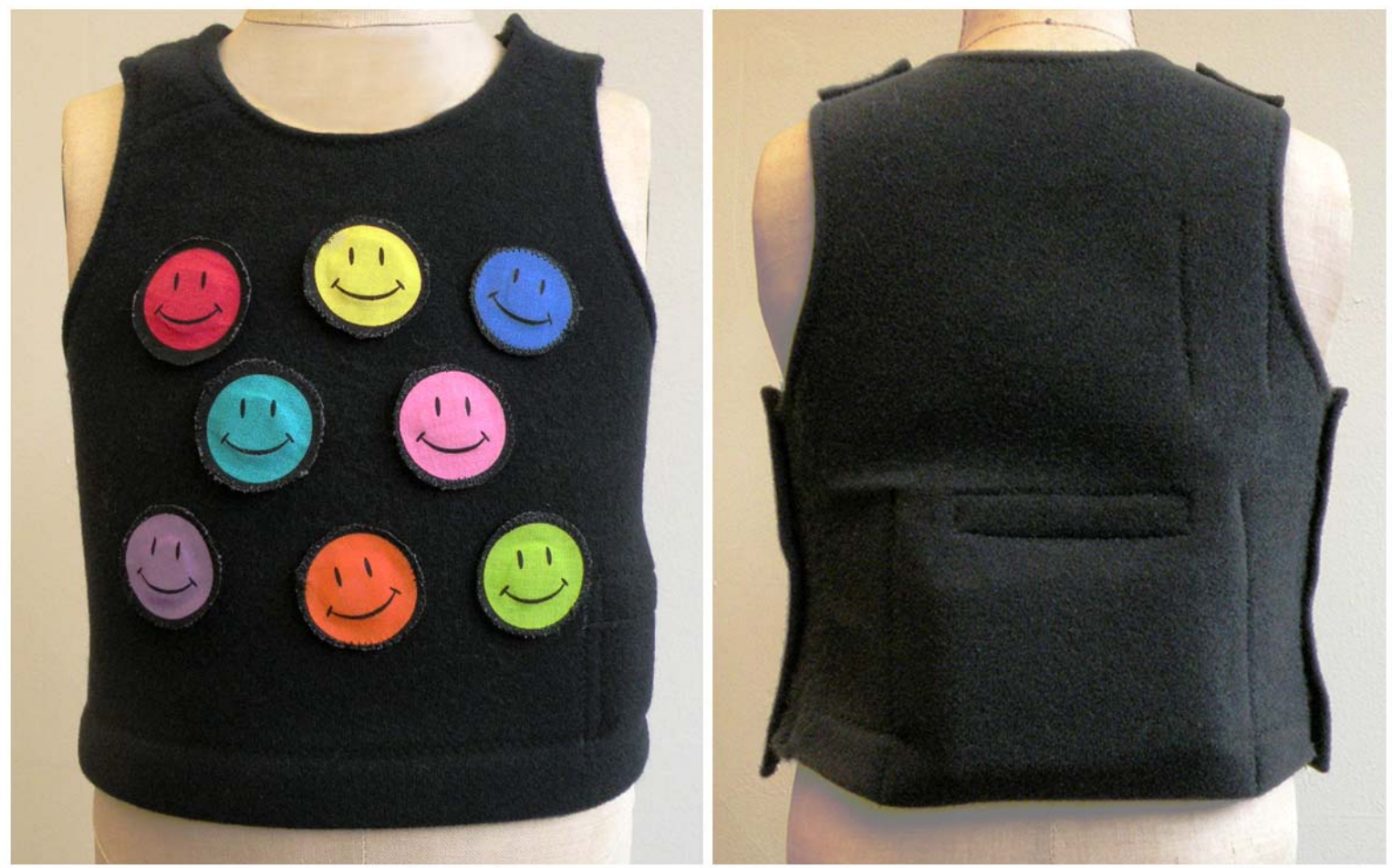

Figure 5. The test garment (Prototype 7a) front and back view on a child dress form. Photo by first author. 


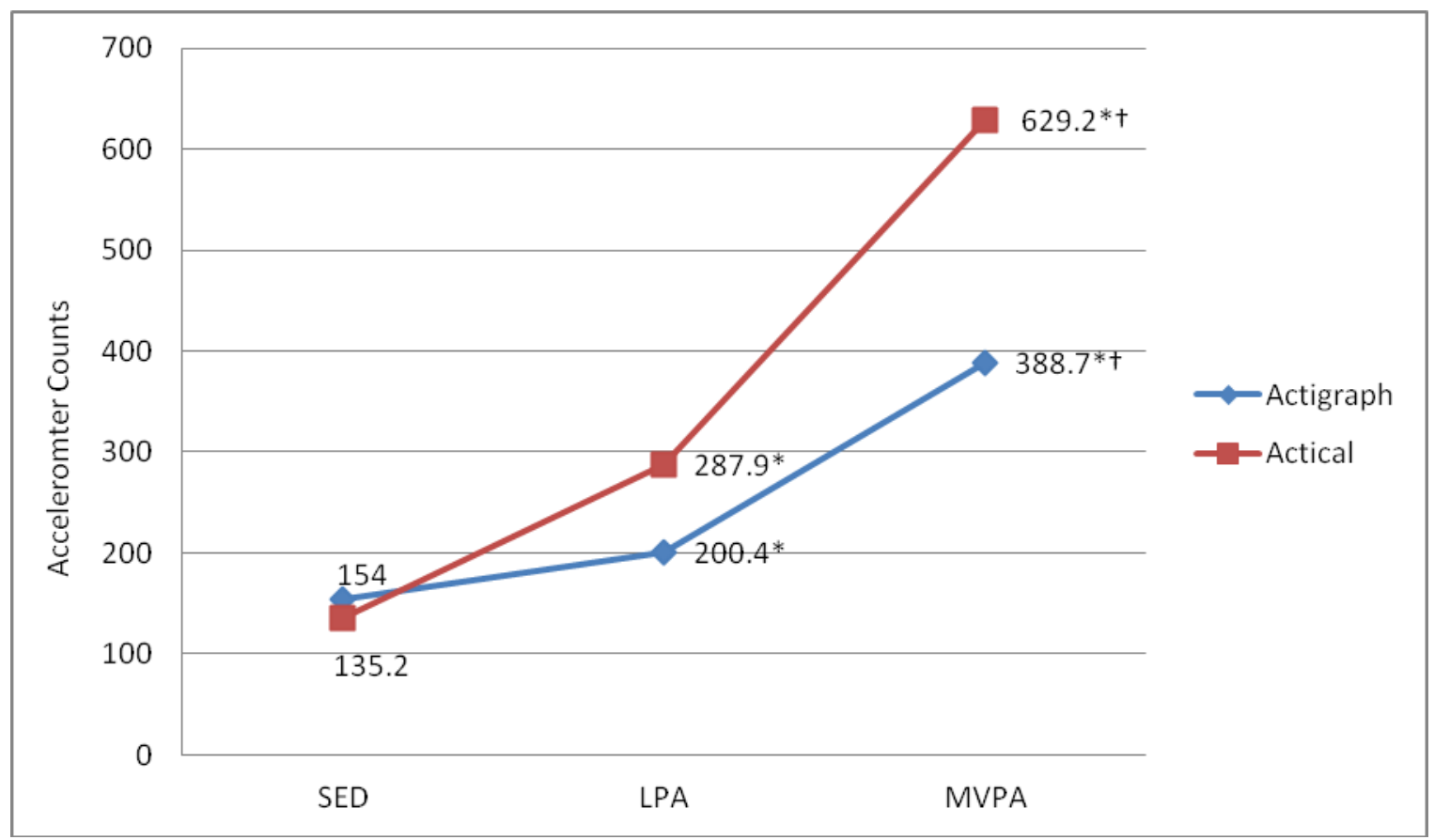

Figure 6. Mean ActiGraph ${ }^{\mathrm{TM}}$ and Actical ${ }^{\mathrm{TM}}$ accelerometer counts recorded during $15 \mathrm{sec}$ observation intervals coded as sedentary (SED), light physical activity (LPA), and moderate to vigorous physical activity (MVPA).

* denotes significant difference from sedentary $(p<.05)$. †denotes significant difference from light $(p<.05)$. 
Table 1

Mean Utterances and Mean Length of Utterances (MLU) as Morphemes of Toddlers Categorized by Type of Movement

\begin{tabular}{lrr}
\hline \multicolumn{1}{c}{ Type of Movement } & $M(n=12)$ & \multicolumn{1}{c}{ MLU } \\
\hline Stationary & .83 & 2.00 \\
Stationary with limb movement & 51.66 & 3.33 \\
Slow or easy & 16.33 & 2.99 \\
Moderate & 16.33 & 2.40 \\
Fast & 2.25 & 3.00 \\
\hline
\end{tabular}




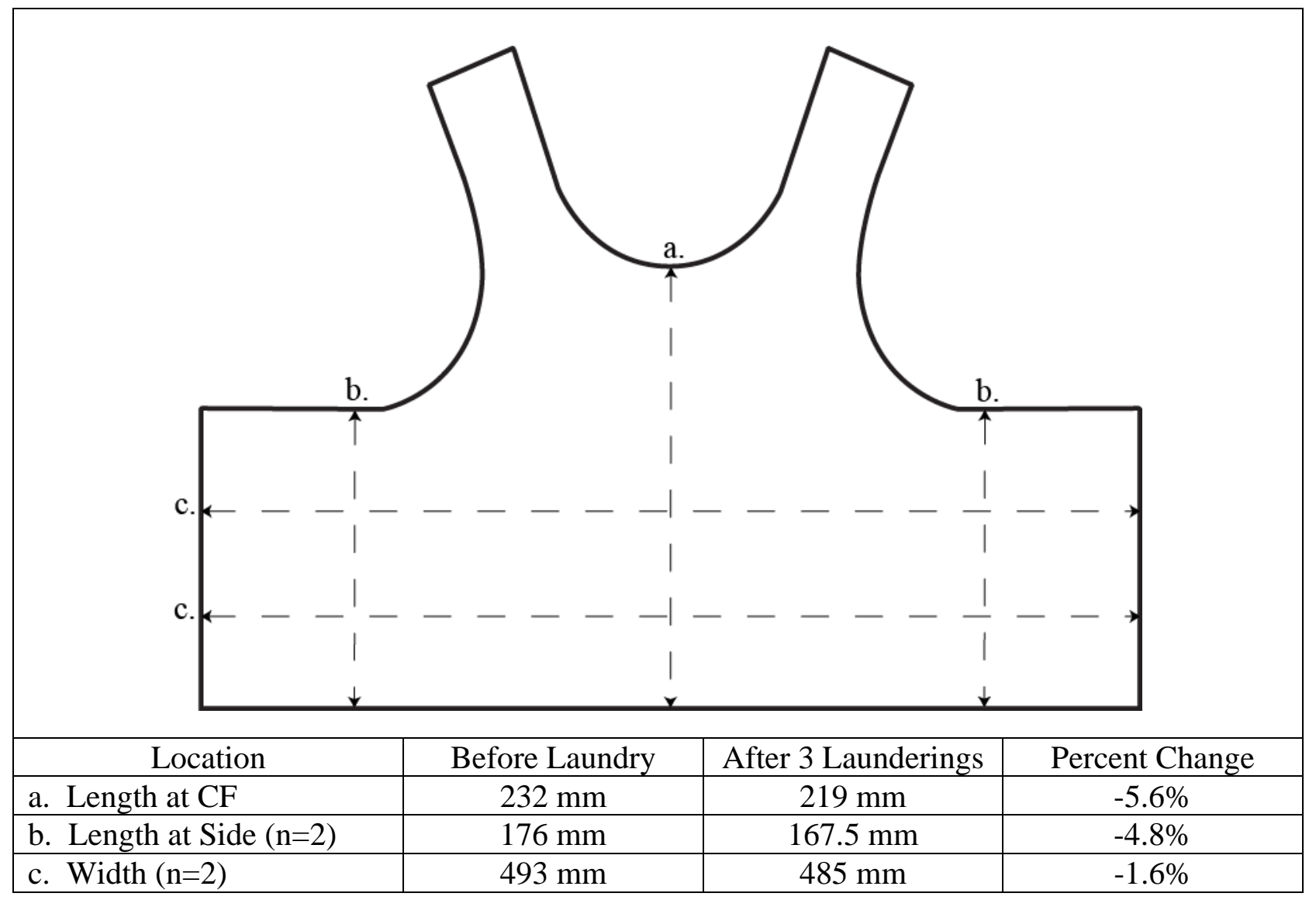

Figure 7. Measurement locations on test garment front for dimensional change evaluation. Measurements before and after three launderings and dimensional change results. 
